\title{
Father Secchi and the first Italian magnetic observatory
}

\author{
N. Ptitsyna ${ }^{1}$ and A. Altamore ${ }^{2}$ \\ ${ }^{1}$ Institute of Terrestrial Magnetism, Ionosphere and Radiowave Propagation, Russian Academy of Science, \\ St. Petersburg Filial, Russia \\ ${ }^{2}$ Physical Department “E. Amaldi”, University “Roma Tre”, Rome, Italy \\ Correspondence to: N. Ptitsyna (nataliaptitsyna@ya.ru)
}

Received: 23 October 2011 - Revised: 19 January 2012 - Accepted: 30 January 2012 - Published: 28 February 2012

\begin{abstract}
The first permanent magnetic observatory in Italy was built in 1858 by Pietro Angelo Secchi, a Jesuit priest who made significant contributions in a wide variety of scientific fields, ranging from astronomy to astrophysics and meteorology. In this paper we consider his studies in geomagnetism, which have never been adequately addressed in the literature. We mainly focus on the creation of the magnetic observatory on the roof of the church of Sant'Ignazio, adjacent to the pontifical university, known as the Collegio Romano. From 1859 onwards, systematic monitoring of the geomagnetic field was conducted in the Collegio Romano Observatory, for long the only one of its kind in Italy. We also look at the magnetic instruments installed in the observatory, which were the most advanced for the time, as well as scientific studies conducted there in its early years.
\end{abstract}

\section{Introduction}

A freely suspended magnet points in the North-South direction. This physical phenomenon was noticed by humans very early and was probably studied in China during the Qin dynasty (3rd century BC). The basis for a science of geomagnetism, however, was only laid much later, from the 13th to the 16 th centuries. In the mid-15th century, scholars observed that a hanging magnet does not always point to the North. This led to the notion of magnetic declination. The first evidence of the inclination of the magnetic field direction relative to the horizontal plane of the Earth appeared in Europe in the mid-16th century.

In 1600 William Gilbert (1544-1603), the royal physician to Queen Elizabeth I, published very important results on terrestrial magnetism in his great treatise De Magnete. In this book he announced that the Earth itself was a giant magnet. Gilbert argued that the magnetic nature of the Earth was the reason why compasses point North; it had previously been believed that compasses were attracted by the Pole Star (Polaris), or a large magnetic island at the North Pole. Gilbert developed a magnetized sphere representing the Earth, called a "terrella". Moving a small compass around the terrella he demonstrated that a horizontal compass always pointed North-South, while a magnetized needle free to swing about its center of gravity in a North-South vertical plane indicated the proper magnetic inclination between the magnetic force and the horizontal direction (Baigrie, 2007).

At that time magnetic declination and inclination were regarded as constant over time. In 1635 Henry Gellibrand (1597-1637), professor of astronomy at Gresham College (London), recorded geomagnetic field variations over time, so-called secular variations.

In 1832 Carl Friedrich Gauss (1777-1855) and his young assistant Wilhelm Weber (1804-1891) devised a method for using an auxiliary magnet to measure not only the direction of the Earth's magnetic force, but also its intensity. In this way devices for the measurement of all components of the vector representing the magnetic field of the Earth became available. Moreover, a value of the Earth's magnetic field intensity could be replicated by all magnetic instruments and needles; now all such instruments could be calibrated locally, independently of any others (see, for example, Good, 1998; Stern, 2002). A global network of magnetic observatories could now be created and in fact Alexander Von Humboldt (1769-1859) launched a program for establishing a worldwide network of permanent magnetic observatories. As a result of his initiative, in the first half of 19th century the number of magnetic observatories increased so rapidly that the process was dubbed as the "magnetic crusade". After 


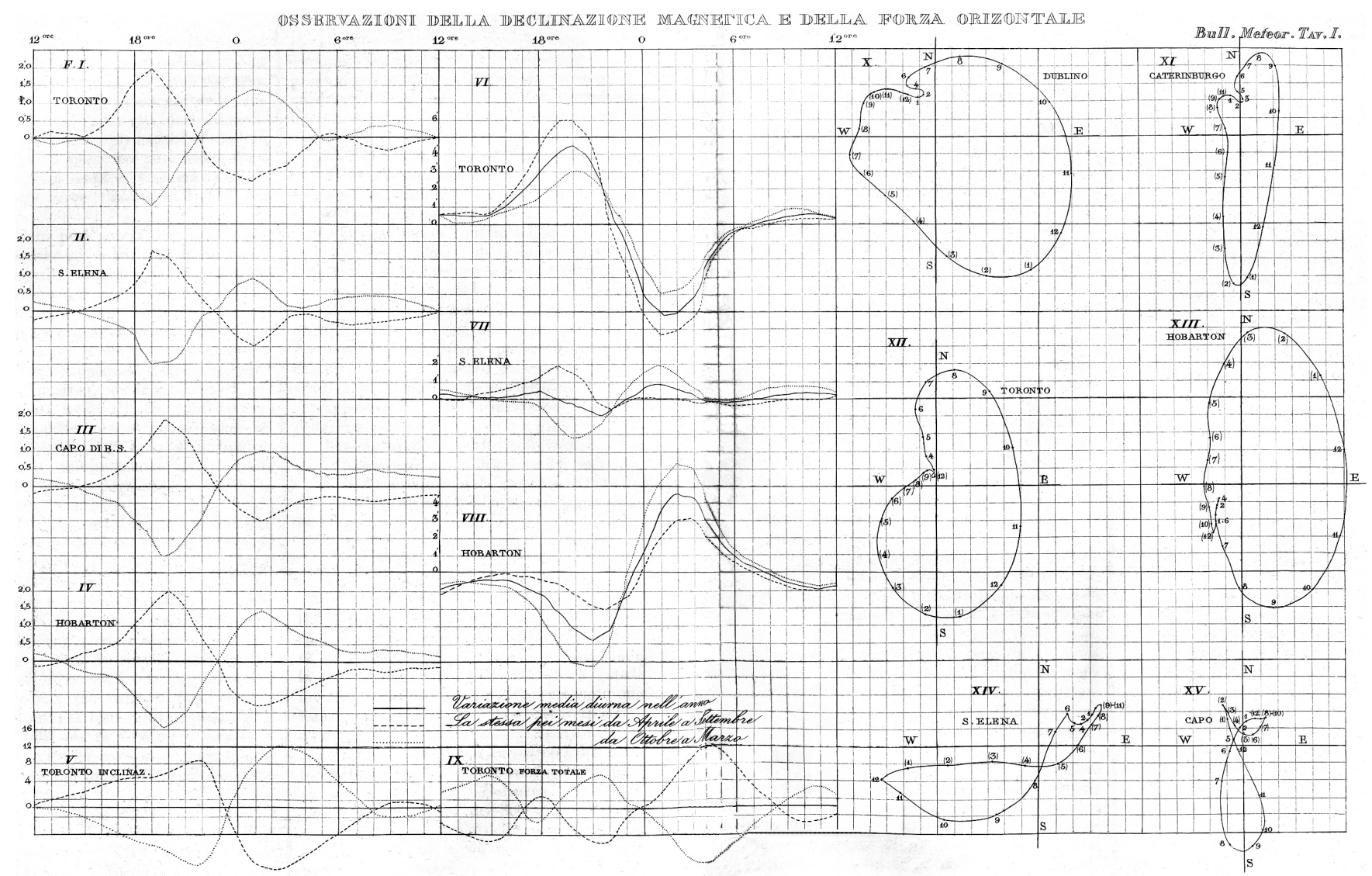

Figure 1. Diurnal variations of magnetic field registered by Humphrey Lloyd in different observatories, as reported by Secchi (1862a).

the work of Alexander von Humboldt and Carl Friedrich Gauss in Germany, Edward Sabine (1788-1883) in Britain, and Adolf Kupfer (1799-1865) in Russia, dozens of observatories were set up in Europe, Siberia, Alaska and in the British overseas territories (Cawood, 1977; Jonkers, 2007; Tyasto et al., 2009; Schröder et al., 2010). The worldwide magnetic observatory network supported a wide range of geomagnetic studies, as is illustrated by the example in Fig. 1 (Lloyd, 1862; Secchi, 1862a).

In Italy studies measuring the Earth's magnetic field have a long history (Lanza et al., 2005; Meloni et al., 2007). The earliest documented measurements can be found from the mid-16th century on (Cafarella et al., 1992a; Cafarella et al., 1992b), while the first systematic observations of the magnetic vector began as progress was being made in geomagnetism in the 19th century. There is general agreement that the establishment of an Italian geomagnetic observatory was only first proposed in 1880 (Basso-Ricci, 1997; Chiappini, 2007; Meloni et al., 2007). The first permanent magnetic observatory in Italy was then actually built in 1858 by the Jesuit Pietro Angelo Secchi (1818-1878), the director of the Collegio Romano Astronomical Observatory.

Father Secchi was one of the great scientific minds of his time and he made major contributions to a wide variety of scientific fields. He is not only considered to be a founder of astrophysics - he developed the first stellar spectral classification - but also the father of modern Italian meteorology. He gained a worldwide reputation for his invention of the meteorograph, an apparatus for registering changes in the various atmospheric parameters. For this invention Secchi was awarded a prize by Napoleon III at the Paris World Exposition in 1867 (Brenni, 2004).

Here we wish to focus on Secchi's work in geomagnetism, which has not been adequately dealt with in the literature. After discussing the setting up of the permanent Collegio Romano Magnetic Observatory, we will describe its equipment and scientific research conducted there in the early years.

\section{Setting up the Collegio Romano Magnetic Observatory}

As a young man Secchi studied physics and took a great interest in electricity and magnetism, especially terrestrial electric currents (Secchi, 1850). This led him to investigate terrestrial magnetism: he organized systematic monitoring of the Earth's magnetic field and studied its correlation with atmospheric electricity (Secchi, 1862a). In 1853 he began work on constructing a magnetic observatory in the Collegio 
Romano in addition to its existing astronomical and meteorological observatories (Secchi, 1856).

Handbooks for observatory practice (e.g. Wienert, 1970; Jankowski and Sucsdorff, 1996) provide descriptions of the buildings needed for a manned magnetic observatory with classical instruments recording geomagnetic variations and absolute measurements. There are three main requirements for a magnetic observatory building: stable pillars for the sensors, a constant temperature and non-magnetic materials for the building interior. For the foundations, bedrock is recommended, though this is rarely actually possible. Moreover, in the observatory area magnetic field there should be no differences greater than a few $\mathrm{nT}$ between the $10 \mathrm{~m}$ points. The place for absolute measurements should be free of horizontal and vertical gradients.

The Collegio Romano Magnetic Observatory was installed on the roof of the baroque church of Sant'Ignazio, where Secchi's astronomical observatory had been relocated in 1856. According to Secchi, the geographical coordinates were: latitude $=41^{\circ} 53^{\prime} \mathrm{N}$; longitude $=0^{\circ} 40^{\prime} 34^{\prime \prime} \mathrm{E}$ (from Paris). The observatories were situated at an altitude of $58.5 \mathrm{~m}$ above sea level. The church building was an ideal base for both observatories, since it had originally been designed to support a monumental dome. This design was abandoned, however, and the monumental dome was replaced by a false dome painted on the church ceiling by Andrea Pozzo (1642-1709). The observatories were thus erected on the roof around the false dome (see Fig. 5).

Secchi described the advantages of the position of the observatory (Secchi, 1861):

"La sala degli strumenti e' bassata su un solido rinfianco della gran fabbrica della chiesa, di solidita tutta prova, $e$ cinta da mura grosse $1.5 \mathrm{~m}$, onde la temperatura vi assai costante." ("The instruments room was built on the solid structure of the great church, whose solidity was proven, and surrounded by thick walls of $1.5 \mathrm{~m}$ to keep a very constant temperature inside.")

The Observatory occupied a room $9.30 \mathrm{~m}$ long and $5.25 \mathrm{~m}$ wide; its remains can still be seen on the church roof.

The main requirement for magnetic observatories is the absence of magnetic material in the vicinity of the sensors. In practice this means that everything has to be tested: concrete, bricks, roof, metal parts, etc. Secchi went to great lengths to obtain a non-magnetic environment in the observatory, including the very expensive operation of removing all the iron from the rooms dedicated to the instruments. He also conducted meticulous testing of magnetic effects from non-removable ferromagnetic masses. Although the observatory was equipped mostly with copper and brass instruments, special tests were carried out to estimate the influence of the laboratory environment on magnetic measurements. Secchi dealt with this topic in detail (Secchi, 1861):
"Per quanta cura si sia avuta e spesa si sia fatta per rimuovere tutti i ferri dalle stanze destinate agli instrumenti, e intorno ad esse, tuttavia, non si sono potuti levare che i piu vicini. Esistono ancora a distanza 24 metri, le legature delle incavallature del tetto, e a distanza di circa 15 dentro la chiesa $e^{\prime}$ un grande finestrone di ferro, fisso e affatto inamovibile. Furono fatte percio' diverese ricerche per formarsi una idea di quanta potesse essere la influenza di queste masse." ("Despite the great care and expense involved in removing all the iron objects from the instruments rooms and around them, we were only able to eliminate the nearest pieces of iron. At a distance of $24 \mathrm{~m}$, there are still iron bindings in the roof trusses and at a distance of about $15 \mathrm{~m}$ inside the church there is a large, fixed iron window that can in no way be removed. Some tests were conducted, therefore, to evaluate the influence of these iron masses.")

The tests yielded the following results:

"Da cio' possiamo concludere esser il luogo discretamente libero da materiali perturbatori variabili, e competente per osservazioni differenziali; ma per le assolute esser prudenza indispensabile il comparare $i$ risultati quivi ottenuti con quelli avuti alla aperta compagna. Per cio' una stazione fu fissata sul monte Aventino in mezzo ad una vigna di proprietà del Collegio Romano tra S. Prisca e S Sabina distante al Sud dall' oss. magnetico di metri 1853 e al'Est di metri 218. Ivi fu eretto con grossi massi di marmo un sodo pilastro senza cemento." ("Consequently, we can conclude that the place is quite free from various disturbing materials and suitable for differential observations; but for the absolute measurements it will be utterly indispensable to compare the results obtained here with those obtained in open countryside. For this reason, one station was situated in a vineyard on the Aventine hill belonging to the Collegio Romano, between the churches of St. Prisca and St. Sabina, $1853 \mathrm{~m}$ from the magnetic observatory on the south side and $218 \mathrm{~m}$ on the east side. Here a solid pillar was built with large marble blocks and no cement.")

Secchi stressed the last aspect, because he was aware that pillars for absolute measurements must be completely nonmagnetic. In modern observatories the concrete part of the pillar in the absolute house usually only reaches to floor level, while non-magnetic material is used for the rest of the building (Jankowski and Sucsdorff, 1996).

Setting up an observatory requires considerable financial resources. The building of Collegio Romano Magnetic Observatory was generously funded by Pope Pius IX. Interestingly, scientific and technical innovations received considerable support during Pius IX's pontificate (1846-1878). In addition to political reasons, Pius IX was also motivated by his own scientific background (Mazzotti, 2010): he had attended science courses at the Piarist College in Volterra and graduated with a dissertation on the construction of telescopes (Ferretti, 1809). 


\section{The observatory instruments}

There can be no doubt that the heart of an observatory is its scientific equipment. In this section we look at the family of magnetic instruments installed in the Collegio Romano Observatory. When building the new observatory, Secchi ensured that it was equipped with the very latest instruments for magnetic measurements by purchasing them from the Kew Observatory, London. In the second half of the 19th century Kew was the leading institution for the construction of magnetic instruments as well for testing and calibrating them and maintaining standards. Its staff was also responsible for the British Colonial magnetic network. "The Report of the Joint Committee of the Royal Society and the British Association for Procuring a Continuance of the Magnetic and Meteorological Observatories" (Report..., 1857-1859) mentions that:

"M. Secchi, of the Observatory of the Collegio Romano at Rome, has recently been supplied from Kew, at the expense of the Papal Government, with a complete equipment of magnetical instruments, similar to those which have done such good work in the British Colonial establishments."

The magnetic observatory was thus equipped with six apparatuses for measuring the direction and intensity of the geomagnetic field. After testing and calibrating the instruments, the first observations were made in 1858. Regular monitoring of the Earth's magnetic field by all instruments then started in May 1859.

In the history of geomagnetic observations we find a large number of instruments: from ancient compasses right up to present-day sophisticated magnetometric systems. Although conventional magnetic compasses from the mid-19th century are not rare, instruments that had an impact on scientific research are rather unusual. In the 1990s a project was set up to survey and catalogue geomagnetic scientific instruments in Italy. The results of the project conducted by science historians and geophysicists were published in a comprehensive book (Basso Ricci, 1997). Around ten magnetic instruments constructed in the first half of the 19th century were documented, but only one of them came from Secchi's observatory, a balance magnetometer now in the Rome Astronomical Observatory Museum (Basso Ricci, 1997). All Secchi's other instruments are described in detail in his papers (Secchi, 1859a, b, 1861), which are the earliest description in Italy of magnetic devices and methods for geomagnetic measurements as well as of the underlying physics. The third paper (Secchi, 1861) contains two beautiful illustrations (see Figs. 6 and 7) of all the magnetic instruments used in the Collegio Romano. The overall external appearance and individual details of these instruments were drawn and engraved by Giovanni Della Longa (1823-1888), a leading Italian graphic artist in the mid-19th century.

There are two main categories of instruments: the first comprises variometers which measure elements of the geomagnetic field vector in arbitrary units; and the second con- sists of absolute instruments which measure the magnetic field or its components in terms of absolute physical basic units or universal physical constants $(\mathrm{m}, \mathrm{kg}$, s, or their derivatives). Six magnetic instruments were installed in the Collegio Romano Observatory. Three large instruments were devised for variation measurements and three small portable ones were intended for absolute measurements. The positions of the instruments in the observatory room are shown in Fig. 8.

\subsection{The large declinometer}

The declinometer is an instrument used to measure the direction of the horizontal component of the Earth's magnetic field at a given site, i.e. the magnetic declination.

Magnetic declination is defined as the angle between the direction of a magnetic needle and the meridian of the site. In modern times the declination is assumed as positive when the needle points East of geographic North. A declinometer consists of a magnet suspended in a horizontal position by a thin wire. It works like a compass needle. The magnet is equipped with a mirror at one end and is observed through a theodolite telescope, turned in azimuth until its optical axis and the magnet direction are parallel. The angular reading on a precisely divided horizontal circle indicates the direction assumed by the magnet.

Figure 7 (indicated as Fig. 9 by Secchi in the engraving "Tav. II") shows the declinometer that was installed in the Collegio Romano Magnetic Observatory. In this instrument the thread-suspended magnetic "needle" was a bar $60 \mathrm{~cm}$ long and weighing $1320 \mathrm{~g}$. The needle hung on the leg "EB" connected to the column "AB" which was made of very old hard wood and was $3.40 \mathrm{~m}$ long.

To prevent air currents affecting the apparatus, the magnet was placed within a protective box and the mirror $s$ was placed on the supporting thread outside the box, as shown in Fig. 6 (indicated as Fig. 1 by Secchi in the engraving "Tav. I"). In the same Fig. 6 the theodolite is also shown (indicated as Fig. 2 by Secchi). The theodolite was constructed by Ertel from Munich with no steel and iron to be fully nonmagnetic.

In order to determine magnetic declination, in absence of a distant reference mark of a known azimuth, in the 19th century the astronomical meridian was usually calculated by observing the transit of the Sun or the Pole Star. For this purpose, from the theodolite location it was possible to observe the Pole Star through a roof window, which had a zinc cover.

\subsection{Unifilar magnetometers}

The unifilar magnetometer was widely used in the 19th century to determine the absolute declination and horizontal intensity both in magnetic observatories and in expeditions (Secchi, 1861; Basso-Ricci, 1997). They were designed with the highest possible precision and were utilized in the British 


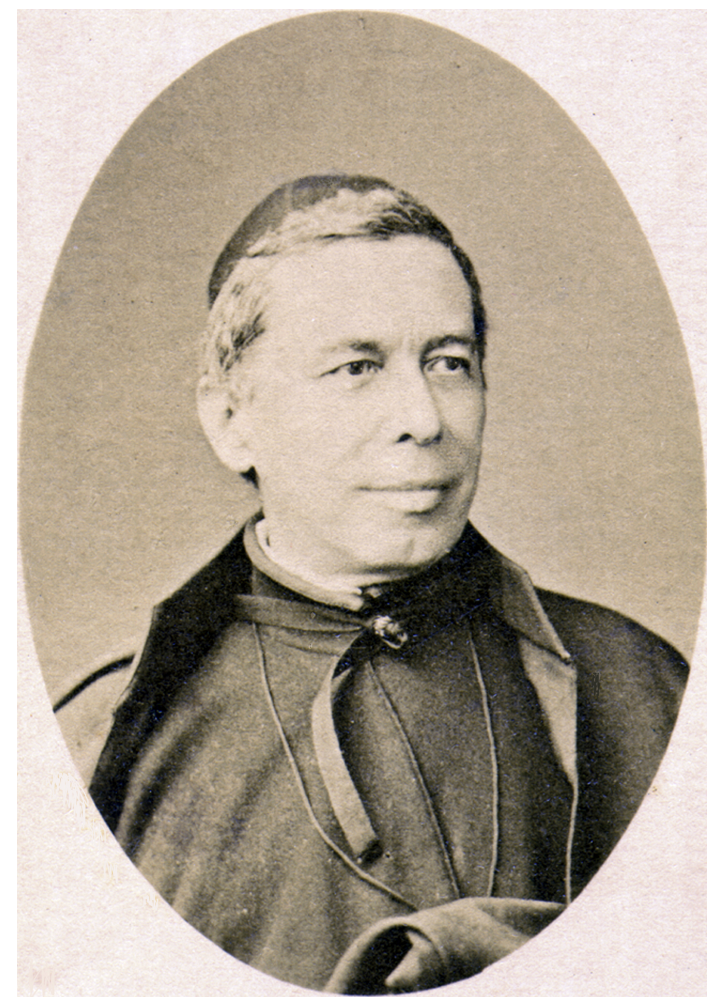

Figure 2. Father Pietro Angelo Secchi (1818-1878).

"magnetic crusade" of the 1840 s and 1850 s and, then later, in the first Italian magnetic survey as well as on the First International Polar Expedition (Denza, 1879; Dawson, 1886; Basso-Ricci, 1997). Two unifilar magnetometers of the Kew Observatory type were used at the Collegio Romano Observatory. Secchi employed these instruments for routine site observations and for calibrating the variometers, as well as for field absolute measurements in Rome and environs. They are shown in Fig. 6 (Figs. 4 and 6 in the engraving "Tav. I").

\subsubsection{The H-magnetometer}

The unifilar magnetometer is shown in Fig. 6 (Fig. 6 in the engraving “Tav. I"). It was utilized for measuring the absolute horizontal component $H$ of the geomagnetic field by the Gauss method (Jacobs, 1987; Jankowski and Sucksdorff, 1996). The method is based on the measurement of the free oscillation period of a magnet of known magnetic moment $M$ suspended by means of a wire, followed by the determination of the deviation produced by the same magnet on a magnetic needle already in equilibrium in the geomagnetic field. The first measurement gives the product $M H$, the second the ratio $M / H$.

As reported by Secchi (1861) in this instrument the magnet, which consisted of a hollow steel cylinder $76 \mathrm{~mm}$ long and $7 \mathrm{~mm}$ wide, was suspended by a silk filament.

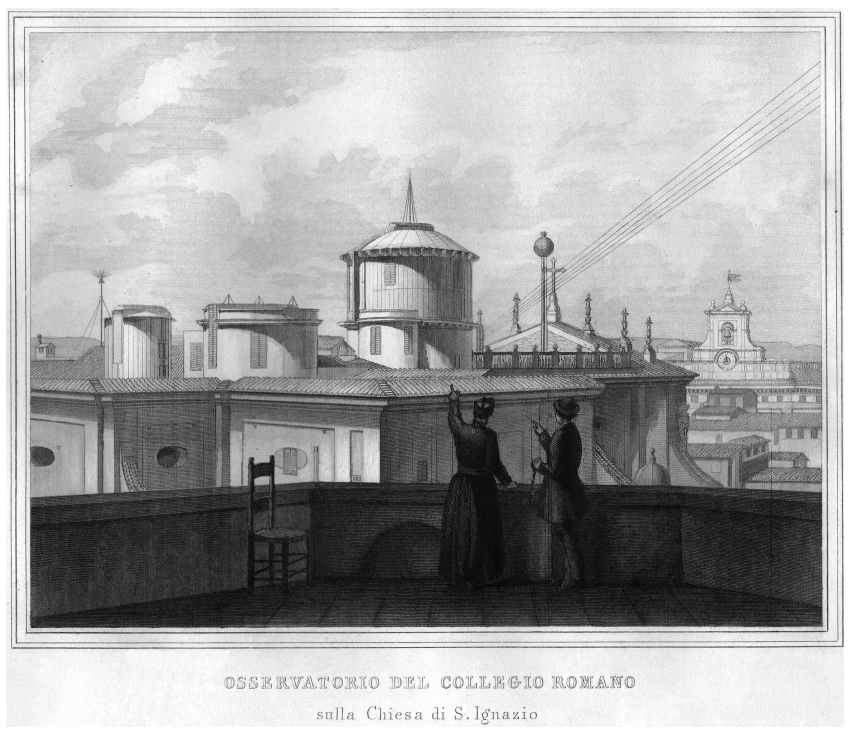

Figure 3. Period etching of the Collegio Romano Observatory on the roof of the church of Sant'Ignazio (from Cacchiatelli and Cleter, 1863).

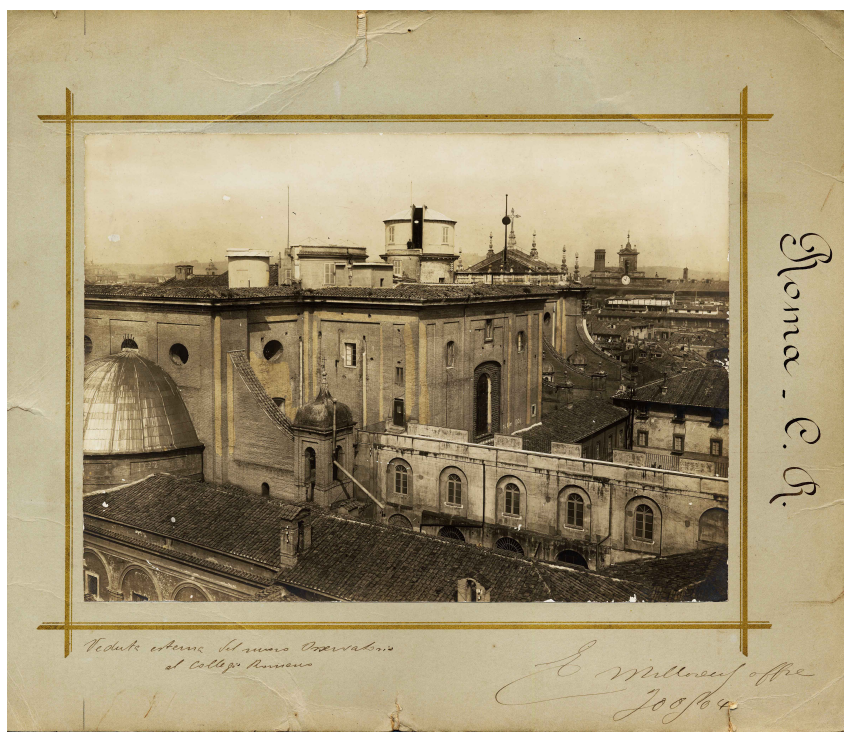

Figure 4. Photograph of the Collegio Romano Observatory (ca. 1900), signed by director Elia Millosevich (1848-1919).

\subsubsection{The portable declinometer}

The portable unifilar declinometer is shown in Fig. 6 (Fig. 4 in the engraving "Tav. I"). In this instrument the magnet consists of a hollow steel cylinder $10 \mathrm{~cm}$ long and $2 \mathrm{~cm}$ wide; it is suspended by a long silk thread, encased by a glass tube (GD). The magnet is protected from air currents by the wooden box $(\mathrm{AB})$. The table (EF) originally belonged to the instrument shown in Fig. 6 (Fig. 6 in the engraving "Tav. I"), but Secchi fixed it to the base of the declinometer to make it easier to transport. 

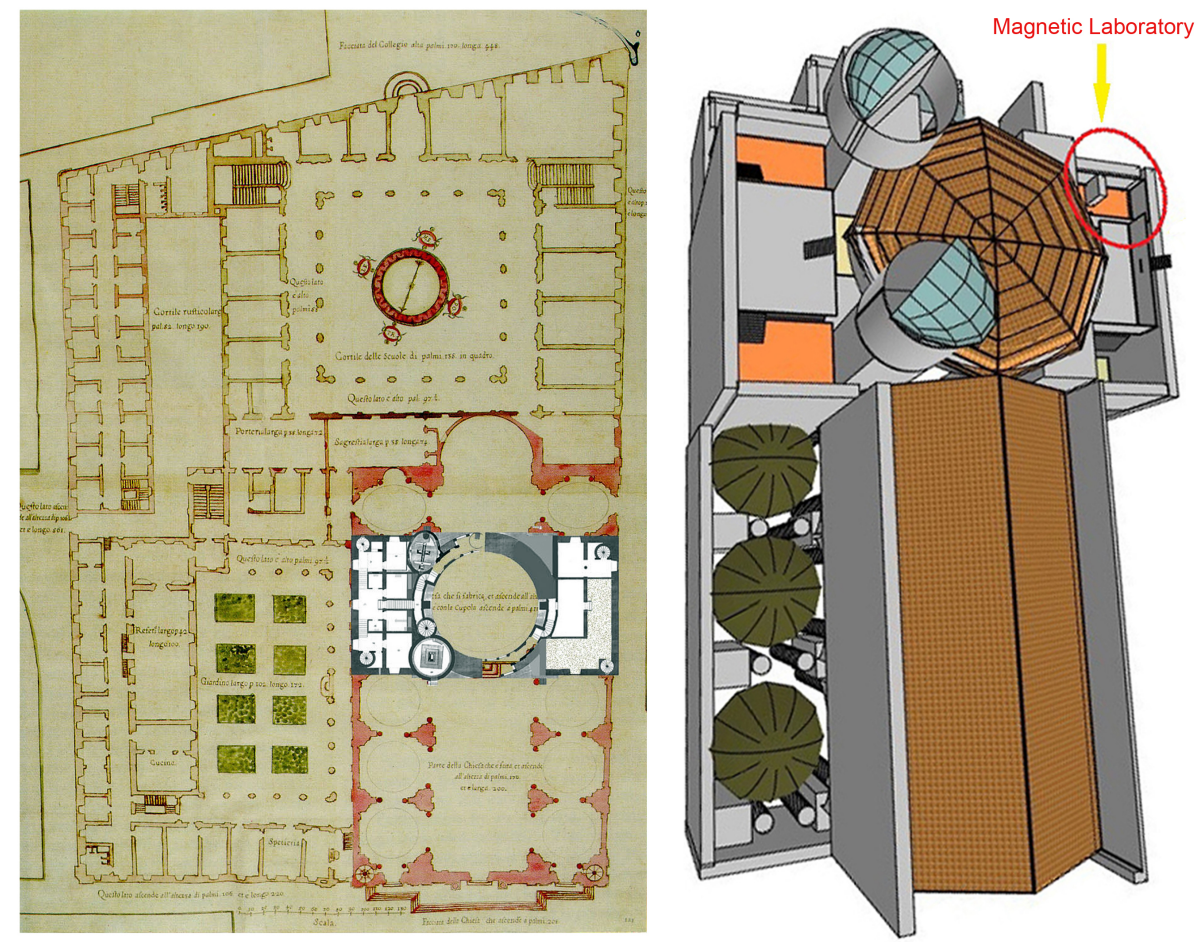

Figure 5. Farther Secchi's astronomical and magnetic observatories on the roof of the church of Sant'Ignazio. Left: map of the Collegio Romano building and the church of Sant'Ignazio (Archivio Storico S. J., Rome). The church map is red and the position of the observatories is highlighted in white. Right: a 3-D picture of the observatories on the church roof. The yellow arrow points to the magnetic observatory, indicated by a red circle. Courtesy of R. Lay.

The determination of the magnetic declination involved two separate steps: (i) the measurement of the magnetic meridian and (ii) the determination of the geographical meridian, obtained through the ephemerides of the Sun and a knowledge of the observation time.

\subsection{The inclinometer}

The inclinometer was used at the Collegio Romano to measure the magnetic inclination, i.e. the angle that the magnetic field forms with the horizontal plane of the site of observation. Secchi (1861) introduces the inclinometer with the following words: "the very elegant instrument, constructed by Barrow from London". It is shown in Fig. 7 (Fig. 7 in the engraving "Tav. II").

The method of measurement is based on the alignment of the axis of the rotating needle along the direction of the magnetic field. If the needle hangs freely in a vertical plane, which coincides with the magnetic meridian, the instrument provides the inclination directly. The needle ( $q q$ in Fig. 7) was $18 \mathrm{~cm}$ long and $4 \mathrm{~cm}$ wide and placed in a mahogany box with glass doors to protect from air currents. The box containing the needle and the graded circle is placed on an azimuthal circle, which can rotate on a tripod base. The horizontal circle has a diameter of $16 \mathrm{~cm}$, and is marked every half degree with minutes established by a vernier. The axis of the vertical circle has two agate flats which are located horizontally. The needle can turn onto the flats. A button " $F$ " is used to lift the needle and lower it into the center of the agate flats. A diametral bar (alidade) carries two microscopes "m", $9 \mathrm{~cm}$ long with a grid, through which both needle tips can be collimated.

These kinds of instruments were widely used in 19th century (see e.g. Multhauf and Good, 1987; Vaquero, 2008). Denza (1834-1894), for example, employed one in the first Italian magnetic survey in 1871-1888 (Basso-Ricci et al., 1997). Denza's instrument, which is practically identical to Secchi's inclinometer is now in the Collegio Alberoni (Piacenza, Italy).

\subsection{The bifilar magnetometer}

The bifilar magnetometer is shown in Fig. 7 (Fig. 8 in the engraving "Tav. II") in a 1:8 scale drawing. In 1832 Gauss announced his method for obtaining the absolute magnitude of the H-field. Then in 1837 he determined the principle of the bifilar magnetometer (Gauss, 1838) and installed this first variometer at the Göttingen observatory. Similar types of instruments were in use in many magnetic observatories in countries from the United States to Russia throughout the 


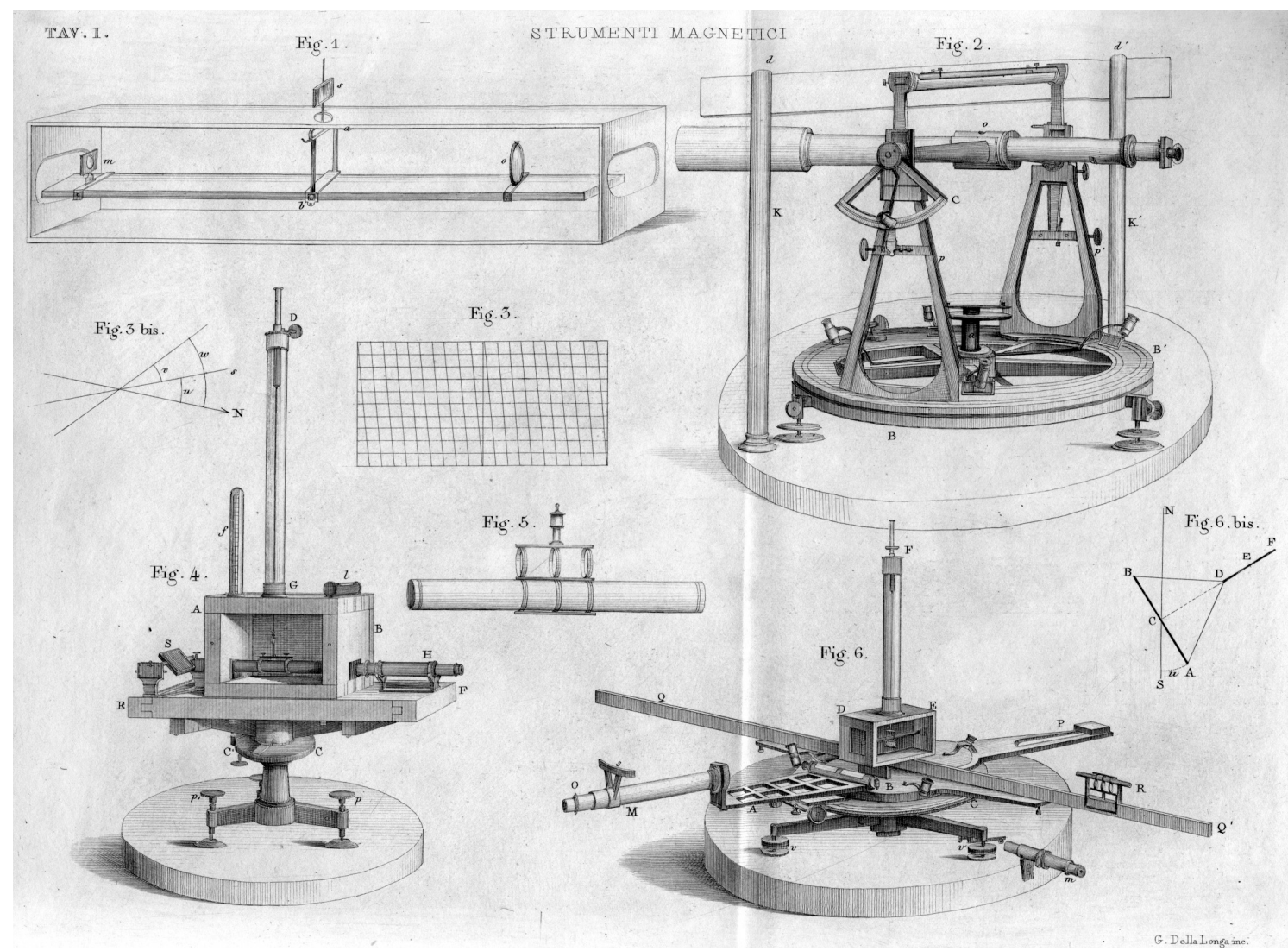

Figure 6. Plate I (“Tav. I”) showing the instruments installed in the Collegio Romano Magnetic Observatory (Secchi, 1861).

19th century (see e.g. Kreil, 1840; Kupfer, 1855; Basso Ricci et al., 1997; Nevanlinna, 1997; Tyasto et al., 2009).

The variations in the horizontal component are determined by using a magnet suspended on two wires (bifilars). Magnet deviations under the action of the geomagnetic field variations are read using a telescope with a scale. The underlying idea of the method for determining variations in the horizontal component with the help of a bifilar is as follows.

Magnet " $a$ ' a" is suspended horizontally on two filaments (Aa' and Ba), as shown in Fig. 6, "'Tav. I", Fig. 8bis). When the device is installed, the upper level (AB) that fixes the filaments is turned around the vertical axis by the angle $v$ until the magnet axis is located in the plane perpendicular to the magnetic meridian $t$. In this situation, the magnet position depends on the equilibrium of two forces: the horizontal component, which tends to move the magnet in the magnetic meridian plane, and the directing force of the filaments, which tends to turn the magnet in the opposite direction. The second of these forces can be considered constant; the horizontal component changes in time, however, as a result of which the magnet position also changes. The condition of equilibrium can yield a change in the horizontal component $(\Delta H)$ expressed as a fraction of the absolute $\mathrm{H}$-value (Kupfer, 1855; Secchi, 1861):
$\Delta H / H=A n+B\left(t-t_{0}\right)$,

where $A$ and $B$ are the constants determined from observation, $n$ is the number of divisions by which the scale moved in the telescope field of view during the known time interval, and $t-t_{0}$ characterizes the corresponding change in temperature.

\subsection{The field balance magnetometer}

The balance magnetometer (Fig. 9) is the only surviving magnetic instrument from the Collegio Romano and is now in the Rome Astronomical Observatory Museum (Monaco, 1997). This instrument, called Lloyd's balance, was used for investigating and mapping the vertical intensity and, in some cases, the horizontal intensity (Jankowski and Sucsdorff, 1996). In the Collegio Romano Observatory it was employed to measure the vertical component $Z$ of the geomagnetic field.

Humphrey Lloyd (1800-1881) first introduced an instrument and a method for measuring the vertical force around 1842. This device was then found in many magnetic observatories by the mid-19th century (McConnell, 1980; Multhauf and Good, 1987; Basso Ricci et al., 1997). 


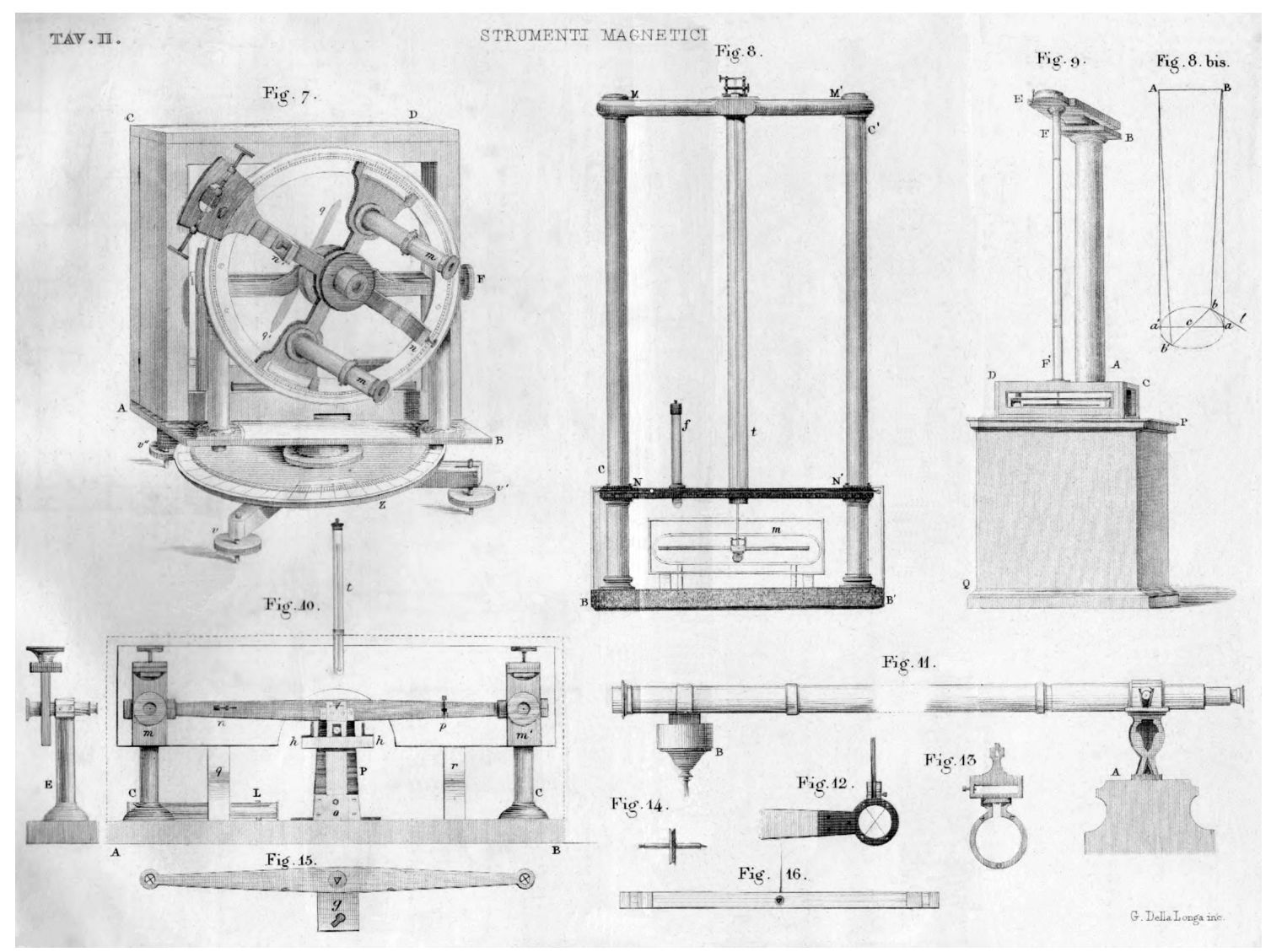

Figure 7. Plate II (“Tav. II”) showing the instruments installed in the Collegio Romano Magnetic Observatory (Secchi, 1861).

The magnetometer shown in Fig. 7 (Fig. 10 in the original engraving) has a $30.5 \mathrm{~cm}$ magnet " $\mathrm{mm}^{\prime}$ " supported by an agate edge. The zero reading corresponds to the horizontal position of the magnet, which means that the magnetic moment is in balance with the gravity force $g$. Deviation from this position is a measure of the magnetic field component. This instrument is a variometer. It indicated changes in the vertical force directly and could be used for measuring vertical field variations on an hourly or daily basis.

\section{Magnetic observations}

Farther Secchi clearly had a scientific program of observations in mind for the magnetic observatory, which was equipped with the latest instruments. He illustrated his program as follows (Secchi, 1861):

1. Determination of the three elements, declination, inclination and horizontal intensity of the Earth's magnetic field, which has not been determined for many years;

2. Observation and analysis of diurnal variations of these three elements in the magnetic field at a station characterized by frequent major perturbations;
3. Study of large magnetic field perturbations in the area of the volcanic Albani Hills, near Rome;

4. Analysis of the correlation between magnetic and meteorological variations;

5. Testing and improvement of magnetometers and comparison with instruments used in other observatories.

When Secchi began regular monitoring of the Earth's magnetic field in May 1859 he acquired precise knowledge of the times and the geographical locations by means of astronomical observations. His primary objectives were testing, calibrating and improving his new instruments as well as maintaining standards. To achieve more accurate results and to make the instruments easier to use, he introduced various kinds of changes and innovations to the magnetometers and to the methods of measurements (Secchi, 1861). He also conducted special experiments to find and check temperature and torque coefficients, to define scale values of the magnetometers, etc.

Figure 10 shows page 31 from Secchi's work (1861), in which the results for the temperature coefficient for bifilar magnetometers are presented. In this experiment Secchi used 


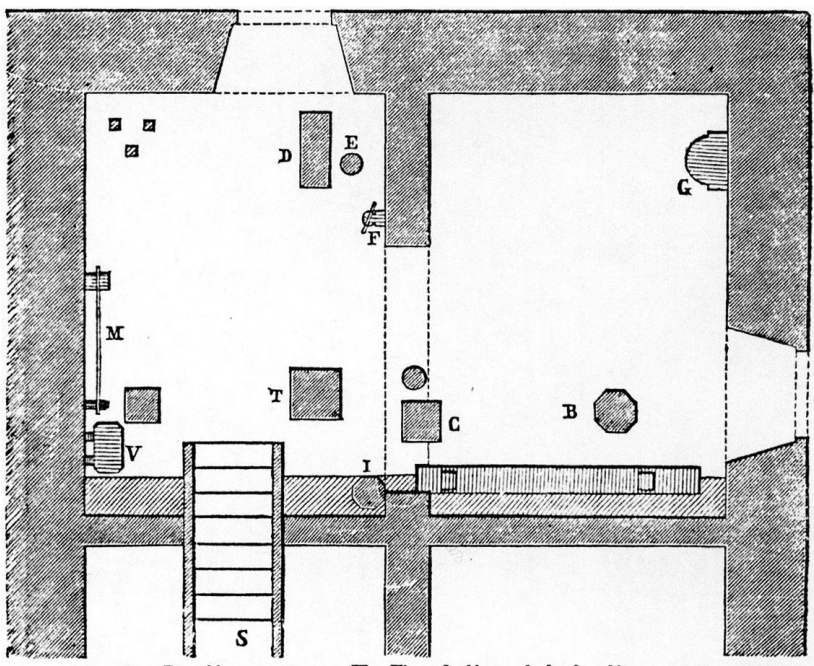

D. Declinometro. T. Teodolite del declinometro.

$B$. Magnetometro bifilare : $C$ cannocchiale per la sua lettura.

V. Magnetometro verticale a bilancia, $M$ suo microscopio per la lettura.

G. Declinometro portatile.

$I$ inclinometro.

H. Magnetometro per determinare l' intensità.

$F$. collimatore del declinometro (1).

Figure 8. Plan of the magnetic observatory room showing the position of the instruments (Secchi, 1861).

hot water and vapor to vary the temperature of bifilar magnetometers.

The main aim of Secchi's research was to determine the absolute values of declination, inclination, and horizontal intensity at the Collegio Romano Observatory and at various stations in Rome and environs. The two points in Rome were: (1) Vigna di S. Sabina on the Aventino hill; this station was taken by Secchi as the standard; (2) The garden of the Hotel Russie on the Pincio hill. To study magnetic anomalies related to the volcanic Albano Hills area, a magnetic survey of absolute inclination at 11 stations was conducted.

At the magnetic observatory absolute determinations were made as a check on the "differential instruments" and to study long-term (secular) changes. Accurate secular variation information is one of the most important objectives of permanent magnetic observatories. To investigate secular variations, Secchi turned to measurements made earlier in Rome by other scientists. Thus, for example, the absolute value of inclination found by Secchi in $1859\left(I=59^{\circ} 12^{\prime}\right)$, as compared with data obtained by Humboldt and Gay Lussac in 1806 and other authors (Quetelet, 1840; Quetelet, 1841), gave a secular change of $3.09^{\prime} /$ year for the first decades of 19th century (Secchi, 1961).

Regular observations of all magnetic components were usually noted 10-12 times a day (from 07:00 to 21:00). Special attention was paid to specific periods. "Extraordinary

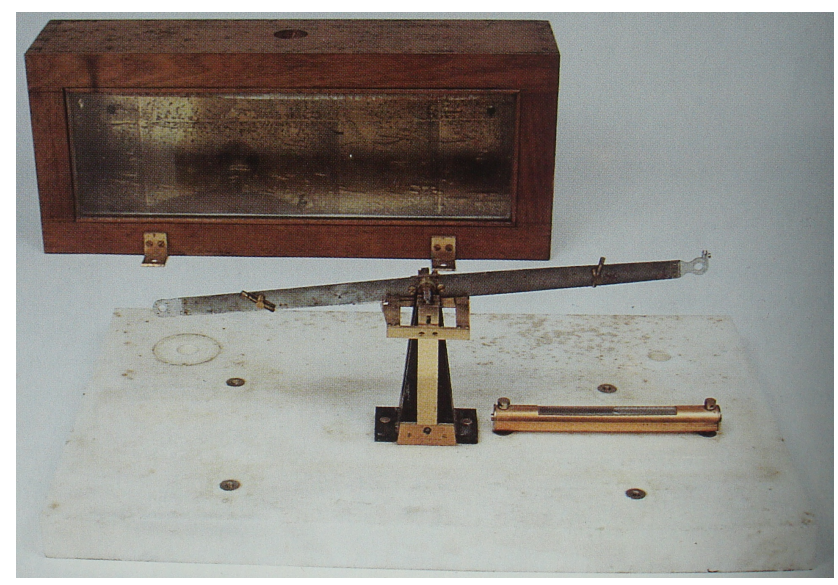

Figure 9. Lloyd's "vertical force magnetometer" (or "balance magnetometer") used in Secchi's magnetic observatory (Astronomical Observatory Museum, Rome).

observations" were made when marked changes were noticed, especially during polar aurora phenomena, which at that time could easily be observed even in the centre of Rome, where the Collegio Romano was situated (Secchi, 1861, 1872). These special observations were made at least every $10 \mathrm{~min}$.

The results of Secchi's "extraordinary observations" are presented in tabular form Secchi (1861). He compiled a full list of principal geomagnetic field disturbances observed at the Collegio Romano Magnetic Observatory from June 1858 to June 1860. Data on declination, horizontal and vertical components were accompanied by detailed information on meteorological conditions and comments on aurora events, when present.

The "extraordinary observations" include some fascinating and extremely important measurements made during the famous magnetic storm on 2 September 1859. The first visual observation of the solar flare (Carrington, 1860; Hodgson, 1860) on 1 September 1859 was followed about $18 \mathrm{~h}$ later by an intense geomagnetic storm at the Earth. The magnetic storm was extreme in terms of several parameters: the solar wind velocity; the southward expansion of the aurora and the geomagnetic disturbance value (Tsurutani et al., 2003). The largest recorded geomagnetic storm in the last $500 \mathrm{yr}$, as measured by high-energy proton radiation (McCracken et al., 2001), it attracted a good deal of public attention at the time because of the widespread aurora borealis and the disruption to telegraph transmissions. Many reports on the September event were collected and published (Loomis, 1859, 1860a, b, c). On 21 September 1859, Secchi wrote a summary of observations of the storm in a letter to the Director of the Paris Astronomical Observatory, M. Le Verrier (1811-1877). The letter was published the same year in Comptes Rendus (Secchi, 1859c) and later also by Loomis (Loomis, 1860c). Secchi reported: 
MAGNETOMETRO BIFILARE

TAV. VI. Sperimenti per determinare il coepriciente DI temperatura del BiflLare.

(10 APRiLE).

\begin{tabular}{c|c|c|c}
\multicolumn{1}{c|}{ Tempo. } & $\begin{array}{c}\text { Bifilare } \\
\text { grande }\end{array}$ & $\begin{array}{c}\text { Tempe- } \\
\text { ratura. }\end{array}$ & Bif. pic. e suo \\
term.
\end{tabular}

SPERIENZA 2..$^{a}$ (11 APRILE).

\begin{tabular}{c|c|c|c} 
Tempo. & $\begin{array}{c}\text { Bifiare } \\
\text { grande }\end{array}$ & $\begin{array}{c}\text { Tempe- } \\
\text { ratura. }\end{array}$ & Bif. pic. e suo \\
term.
\end{tabular}

(a Messo il vapore. $\quad\left(b 1 .^{\circ}\right.$ Massimo.

(c Si leva il vapore. ( $d$ Minimo di deviazione.

Figure 10. Summary of experiments for determining temperature coefficients of bifilar magnetometers (Secchi, 1861). The results were obtained on 10 (left) and 11 (right) April 1859. The tables show time (1st column), data of the large declinometer in divisions of scale (2nd), its temperature ( $3 \mathrm{rd})$ and the reading of the portable bifilar with its temperature $t$ (4th).

"A remarkable disturbance of the magnetic instruments occurred on September 1st and 2nd. At 4 p.m. Sept. 1st, the vertical magnetometer went off its scale, showing a diminution of vertical force. On Sept. 2nd, at 7 a.m., the magnets were greatly disturbed. At 7:10 a.m. the declinometer pointed $2^{\circ} 50^{\prime}$ to the West of its normal position. After this the needle returned rapidly to the East, and at 7:30 a.m. pointed $1^{\circ} 23^{\prime}$ East of its mean position, thus describing an arc of $4^{\circ} 13^{\prime}$ in less than half an hour. This disturbance is the more remarkable, as the greatest range heretofore observed at Rome was only 45' or 50'. The bifilar indicated a diminution of the horizontal component, amounting to 0.129, or about one-eighth of its mean value. These disturbances continued with variable intensity all day. At 4:15 p.m. the vertical magnet again went off its scale. At 9 p.m. the magnet was more subdued, and by midnight the instruments had all returned nearly to their normal condition. The variations of the declinometer, the bifilar and the vertical magnetometer were not simultaneous, and their maxima occurred at different times. The great vibrations were contemporaneous with the currents observed on the telegraph lines. The clouds observed in the heavens had the exact appearance of those of the aurora borealis when it occurs by day, and such as were noticed at Rome on Aug. 29th." (Quoted in Loomis, 1860c). 
Simple estimations give a perturbation in the horizontal component in Rome, amounting to $3000 \mathrm{nT}$ during the geomagnetic storm (Boteler, 2006). This value of the extreme magnetic disturbance recorded on 2 September 1859 is very important in studying the Carrington solar-terrestrial event, since magnetic readings in all other observatories, except Colaba, were off the scale (see, for example, Tyasto et al., 2009).

Secchi attempted several correlations based on the compiled data describing day-to-day variations of Rome's geomagnetic field and weather (Secchi, 1861, 1862b). In the 19th century relations between the magnetic field and weather variations seemed to be taken for granted, in accordance with the ideas of the unity of natural phenomena (Secchi, 1864). Humboldt and Edward Sabine were especially impressed by the similarities between the globe's isothermal lines and the lines of equal magnetic intensity (Good, 1998). Secchi was also strongly influenced by these ideas.

A more detailed retrospective analysis of the results of magnetic field monitoring and research conducted at the Collegio Romano will be presented elsewhere.

\section{Conclusions}

The permanent observatories monitoring geomagnetic phenomena in the early decades of the 19th century have contributed greatly to our understanding of the dynamics of the Earth's magnetic field. According to a guide on the organization of a geomagnetic observatory (Wienert, 1970): "The creation of a geomagnetic observatory is an ambitious enterprise which entails considerable financial commitments. Even more of a burden is the maintenance of the installation and the processing of data." Seen in these terms, Father Secchi's ambitious project was wholly successful.

Secchi's contributions to geomagnetism from the observational, theoretical, organizational and educational points of view can hardly be overestimated. The magnetic observatory on the roof of the church of Sant'Ignazio designed and installed by Secchi in 1853-1858 was for long the only one of its kind in Italy. And he used the most advanced magnetic instruments and method of measurements in his day.

He not only published his scientific results in the foremost European journals, but he also issued regular "Memoirs" containing data and the scientific results from his astronomical, meteorological and magnetic observatories. In 1862, he began publication of the Bullettino meteorologico dell' Osservatorio del Collegio Romano. This meteorological bulletin of 96 to 192 pages appeared regularly for seventeen years, until the time of his death.

After the unification of Italy in 1870, the Collegio Romano building and observatory became state property. The new Italian government, however, did not interfere with work of the by now internationally renowned Secchi and the observatory remained under Vatican control. Father Secchi continued as director until his death in 1878 . When the Uffi- cio Centrale di Meteorologia (Central Meteorological Office) was founded in 1877, Secchi was appointed as the first president by the Italian government. In 1879 this office was transferred to the Collegio Romano, and today is still in the same building under the name of Unita' di ricerca per la climatologia e la meteorologia applicate all' agricoltura (CRA-CMA). The "Climate and Meteorological Research Unit" inherited a meteorological and geophysical library and some of the meteorological instruments once belonging to the Collegio Romano Observatory. The magnetic instruments, spare parts and accessories, however, were dispersed. Some are now in the Astronomical and Copernican Museum at the Rome Astronomical Observatory together with a number of Secchi's astronomical instruments and his celebrated automatic meteorograph.

Acknowledgements. Our thanks to Franca Mangianti, Antonio Meloni, Renzo Lay, and Stampe Eufemi Roma for providing us with valuable historic material and illuminating discussions. We are grateful to Giorgio Villoresi, Sandro Barbanera, David Kerr and the referee De Santis for their useful comments and suggestions on the paper.

Edited by: G. P. Gregori

Reviewed by: A. De Santis

\section{References}

Baigrie, B. S.: Electricity and magnetism: a historical perspective, Greenwood Press, Westport, USA, 173 pp., 2007.

Basso Ricci, M., Cafarella, L., Meloni, A., and Tucci, P.: Due secoli di strumenti geomagnetici in Italia (1740-1971, Istituto Nazionale di geofisica, Roma, Ed. Compositori, Bologna, 234 pp., 1997.

Brenni, P.: Dal Crystal Palace al Palais de l'Optique: la scienza alle esposizioni universali, Memoria e Ricerca, no. 17, p. 35., 2004.

Boteler, D. H.: The Super Storms of August/September 1859 and Their Effects on the Telegraph System, Adv. Space Res. 38, 159$172,2006$.

Cacchiatelli, P. and Cleter, G.: Le scienze e le arti sotto il pontificato di Pio IX . $2^{\circ}$ edizione, Roma, Stabilimento Tipografico Aureli e C., 1863.

Cafarella, L., De Santis, A., and Meloni, A.: Il catalogo geomagnetico storico italiano, Pubblicazione ING, 160 pp., 1992a.

Cafarella, L., De Santis, A., and Meloni, A.: Secular variation from historical geomagnetic field measurements, Phys. Earth Planet. In., 73, 206-221, 1992 b.

Carrington, R. C.: Description of a Singular Appearance Seen in the Sun on September 1, 1859, Mon. Not. R. Astron. Soc., 20, 13-15, 1860.

Cawood, J.: Terrestrial Magnetism and the Development of International Cooperation in the Early Nineteenth Century, Ann. Sci., 34, 551-587, 1977.

Chiappini, M.: Observatories in Italy, p. 890, in: Encyclopedia of Geomagnetism and Paleomagnetism, edited by: Gubbins, D. and Herrero-Bervera, E., Springer, The Netherlands, 1054 pp., 2007.

Dawson, H. P.: Observations of the International Polar Expedition, 1882-83, Eyre and Spottiswoode, Fort \& London, 326 pp., 1886. 
Denza, F.: Misure Magnetiche in Italia, Meteorologia ItalianaMemorie e Notizie, 23-29, 1879.

Ferretti, G. (Pio IX): Le macchine ottiche: esercizio fisicomatematico, Firenze, Allegrini, 1809.

Gauss, C. F.: Bemerkungen iiberdie Einrichtung and den Gebrauch des Bifilar-Magnetometers, in: Resultate aus den Beobachtungen des Magnetischen Vereins im Jahre 1837, edited by: Gauss, C. F. and Weber, W., 20-37, Göttingen, 1838.

Good, G. A: Geomagnetism, theories between 1800 and 1900, in: Sciences of the Earth: An Encyclopedia of Events, People, and Phenomena, edited by: Good, G. A., Garland, New York and London, p. 911, 1998.

Hodgson, R.: On a Curious Appearance Seen in the Sun, Mon. Not. R. Astron. Soc., 20, 13-15, 1860.

Jacobs, J. A. (Ed.): Geomagnetism, Academic Press, 4, 1987-1991. Jankowski, J. and Sucksdorff, C.: Guide for magnetic measurements and observatory practice, IAGA, Warsaw, 1996.

Jonkers, A. R. T.: History of Geomagnetism, p. 359, in: Encyclopedia of Geomagnetism and Paleomagnetism, edited by: Gubbins, D. and Herrero-Bervera, E., Springer, The Netherlands, 1054 pp., 2007.

Kreil, K.: On instruments and observations at Milan (Letter to A. T. Kupfer), Philos. Mag., Series 3, 14, 241-250, 1840.

Kupfer, A. T.: Instructions Governing Magnetic and Meteorological Observations, Compiled by a Director of the Main Physical Observatory for Magnetic Observatories of the Mining Department, Addition to the Annuaire Magnetique et Meteorologique Annee, 1852.

Lanza, R., Meloni, A., and Tema, E.: Historical measurements of the Earth's magnetic field compared with remanence directions from lava flows in Italy over the last four centuries, Phys. Earth Planet. Int., 148, 97-107, 2005.

Lloyd, H.: On Earth currents and their connection with the diurnal change of the horizontal magnetic needle, 11 and 30 November 1861, Irish Ac. Memoirs, Vol. XXIV, Dublin, 1862.

Loomis, E.: The great auroral exhibition of August 28th to September 4th, 1859, Amer. J. Science and Arts, 1st article: XXVIII, 385-408, 1859.

Loomis, E.: The great auroral exhibition of August 28th to September 4th, 1859, Amer. J. Science and Arts, 2nd article: XXIX, 92-97, 1860a.

Loomis, E.: The great auroral exhibition of August 28th to September 4th, 1859, Amer. J. Science and Arts, 3rd article, XXIX, 249266, $1860 \mathrm{~b}$.

Loomis, E.: The great auroral exhibition of August 28th to September 4th, 1859, Amer. J. Science and Arts, 4th article, XXIX, 386399, 1860c.

Mazzotti, M.: The Jesuit on the roof. Observatory sciences, metaphysics and nation-building, in: The heavens on Earth. Observatories and Astronomy in Nineteenth-Century Science and Culture, edited by: Aubin, D., Bigg, Ch., and Sibum, H. O., Duke University Press Durham and London, 58-85, 2010.

McConnell, A.: Geomagnetic instruments before 1900 and illustrated account of their construction and use, Harriet Wynter Ltd, London, 75 pp., 1980.

McCracken, K. G.: Dreschhoff, G. A. M., Zeller, E. J., Smart, D. F., and Shea, M. A.: Solar cosmic ray events for the period 15611994, 1. Identification in polar ice, 1561-1950, J. Geophys. Res., 106, 21585-21598, 2001.
Meloni, A., Cafarella, L., and De Santis, A.: Historical measurements of the geomagnetic field in Italy: a short report, in: Exploring the Earth: Progress in Geophysics since the 17th Century, edited by: Schroder, W., Colacino, M., and Gregori, G., 188-207, 1992.

Meloni, A., Cafarella, L., De Michelis, P., De Santis, A., Di Mauro, D., Dominici, G., and Lepidi, S.: Systematic magnetic observations in Italy, Publs. Inst. Geophys. Pol. Acad. Sc., c-99, 209216, 2007.

Monaco, G.: Catalogo degli Strumenti Scientifici, Museo Astronomico e Copernicano, INAF-OAR, record no. 158, 1997.

Multhauf, R. and Good, G.: A Brief History of Geomagnetism and a Catalog of the Collections of the National Museum of American History, Smithsonian Studies in History and Technology, Smithonian Institution Press, 48, 87 pp., 1987.

Nevanlinna, H.: Gauss' H-Variometer at the Helsinki Magnetic Observatory 1844-1912, J. Geomag. Geoelectr., 49, 1209-1215, 1997.

Quetelet, A.: Geomagnetism in Italy (Manetisme Terrestre en Italie); 1840.

Quetelet, L. A. J.: Sur le magnetisme terrestre en Italie, Bruxelles, 1841.

Report of the Joint Committee of the Royal Society and the British Association, for Procuring a Continuance of the Magnetic and Meteorological Observatories, P. R. Soc. London, 9, 1857-1859, 457-474, 1842.

Secchi, A.: Researches on electrical rheometry, Washington, Smithsonian Institution, Sept. 1850, Vol. III, art 2, 59 pp., 1850.

Secchi, A.: Descrizione del Nuovo Osservatorio del Collegio Romano e Memoria sui lavori eseguiti dal 1852 a tutto aprile 1856, Tipografia delle Belle Arti, 145 pp., Roma, 1856.

Secchi, A.: Introduzione, Memorie dell'Osservatorio del Collegio Romano, Nuova Serie, I-IIX, 1859a.

Secchi, A.: Osservazioni magnetiche, Memorie dell'Osservatorio del Collegio Romano, Nuova Serie, 185-248, 1859b.

Secchi, A.: Sur les perturbations magnétiques obsèrvées a Rome le 2 septembre 1859, (letter du R. P. Secchi à M. Le Verrier), Comptes Rendus, Physique du Globe, T. XLIX, p. 458, 1859c.

Secchi, A.: Descrizione dell'osservatorio magnetico del Collegio Romano, e sunto delle osservazioni fatte nel 1859 e 1860, Il Nuovo Cimento (1855-1868), 13, 1861.

Secchi, A.: Connessione delle variazioni magnetiche colle meteorologiche Bollettino Metereologico, no. 8, 15 June 1862a.

Secchi, A.: ýIntorno alla relazione che passa tra i fenomeni metereologici e le variazioni del magnetismo terrestre, Quattro Memorie, p. 1, Tip. delle belle arti, Roma, 1862 b.

Secchi, A.: L'Unità delle Forze Fisiche, Saggio di Filosofia Naturale, Tipografia Forense, Roma, 1864.

Secchi, A.: Sull' Aurora elettrica del 4 febbraio 1872, Att. Acc. Pontificia Nuovi Lincei Anno XXV, Sess. 3, 18 Feb. 1872.

Schröder, W., Wiederkehr, K.-H., and Schlegel, K.: Georg von Neumayer and geomagnetic research, Hist. Geo Space. Sci., 1, 7787, doi:10.5194/hgss-1-77-2010, 2010.

Stern, D. P.: A Millennium of Geomagnetism, Rev. Geophys., 40, 1-30, 2002.

Tsurutani, B. T., Gonzales, W. D., Lakhina, G. S., and Alex, S.: The Extreme Magnetic Storm of 1-2 September 1859, J. Geophys. Res., 108, 1268, doi:10.1029/2002JA009504, 2003.

Tyasto, M. I., Ptitsyna, N. G., Veselovsky, I. S., and Yakovchouk, 
O. S.: Extremely Strong Geomagnetic Storm of September 23, 1859, according to the Archived Data of Observations at the Russian Network, Geomagn. Aeronomy, 49, 163-173, 2009.

Vaquero, M. A., Valente, R. M., Trigo, Ribeiro, P., and Gallego, M. C.: The 1870 space weather event: Geomagnetic and auroral records, J. Geophys. Res., 113, A08230, doi:10.1029/2007JA012943, 2008.
Wienert, K. A.: Notes on geomagnetic observatory and survey practice, UNESCO, 217 pp., Paris (also in French edition), 1970. 